\title{
Vida, natalidad y libertad en Hannah Arendt: Objeciones a ciertas lecturas biopolíticas del pensamiento arendtiano
}

\section{Life, Natality and Freedom in Hannah Arendt: Objections to some biopolitical interpretations of Arendt's thought}

\author{
JuAN JosÉ Fuentes \\ Universidad de Chile \\ juan.fuentes@uchile.cl
}

RESUMEN. Este trabajo analiza ciertas controversias en torno a las interpretaciones biopolíticas de Arendt. Recientemente, algunos de sus comentaristas han enfatizado las nuevas perspectivas teóricas que ciertos conceptos claves de Arendt («Natalidad», «Libertad», «Poder», «Vida») podrían ofrecer desde el paradigma biopolítico. Sin embargo, estas reinterpretaciones no parecen ser fieles al fundamento original de tales conceptos - la fenomenología-. Intentaré mostrar aquí que es necesario: a) precisar la viabilidad de estas interpretaciones; b) calibrar su alcance; y c) hacer visible el riesgo de operar con ellas una tergiversación del pensamiento aredtiano. Si es plausible mostrar esta incompatibilidad, podremos mostrar también algunos de los límites interpretativos del paradigma biopolítico.

Palabras clave: Arendt, biopolítica, fenomenología, natalidad, mundo.

\section{Preámbulo}

Desde ya algunos años se ha venido hablando de una nueva corriente en filosofía política: La biopolítica. Ésta es deudora de los aportes de filósofos muy disí-
ABSTRACT. This paper analyzes certain controversies that biopolitical interpretations of Hannah Arendt's thought may arise. Recently, several scholars have emphasized that new theoretical clues are made possible through a link between some Arendtian key-concepts («Natality», «Freedom», «Power», «Life») and the biopolitical paradigm. Nevertheless, their studies do not consider enough the original Arendtian background: Phenomenology. Then, it could cause her thought can be misleading. The following steps are required to prove this point: a) to evaluate the viability of the biopolitical interpretations of Arendt's thought; b) to determine their scope; c) to show their risk of producing a misrepresentation of her thought. If this risk can be shown, then the explanating power of the biopolitical paradigm could be considerably relativized.

Key words: Arendt, biopolitics, phenomenology, natality, world.

miles -Nietzsche, Foucault, Agamben, Negri y Espósito, inter alia-, los que, pese a sus diferencias, coincidirían en el siguiente diagnóstico: El problema político fundamental de nuestra época es la imposibilidad de lo político de ser más 
que un suspenso de lo impolítico, un suspenso de nuestra animalidad, de lo biológico y sus pulsiones, de la pura vida en tanto desprovista de propósito, comunidad y sentido, es decir, arrojada a sí misma y a su violencia connatural. Lo acuciante del asunto es que por tratarse de un mero suspenso, lo impolítico siempre amenazaría con retornar.

El paso a lo político consistiría, entonces, en el volverse eso impolítico, político, o, mejor, en el volverse la mera vida, la vida desnuda, un vivir bien, cualificado. Dicho brevemente, se trata aquí del paso de la zoe al bios, tal y como ambos conceptos habrían sido pensados por el mundo griego, en particular, por Aristóteles en su Politika o su Peri psyches. Es en este sentido que G. Agamben insiste en que para los griegos: «Zoe [...] expresaba el mero hecho de vivir, común a todos los seres vivos (animales, hombres o dioses) y bios [...] indicaba la forma o manera de vivir propia de un individuo o grupo [...], pues no se trataba en modo alguno de la mera vida natural, sino de una vida cualificada, de un modo de vida particular)»(Agamben, 2003: 15). Para Agamben, tal singularización de la vida sería así propia del origen de lo político, y actuaría cada vez como su puesta en escena o, en la formulación de Agamben, «como si la política fuera el lugar en que el vivir debe transformarse en vivir bien y fuera la nuda vida lo que siempre debe ser politizado. La nuda vida tiene [...] el singular privilegio de ser aquello sobre cuya exclusión se funda la ciudad de los hombres» (Agamben, 2003: 16-17).

De acuerdo a esto, Agamben parece querer decir que el paso de la zoe al bios politikos es a tal punto incondicionado que, paradójicamente, sólo en razón de que el hombre no es exclusivamente un animal político puede vivir políticamente y que es como zoon logon echon, es decir, como «animal dotado de lenguaje», que opera en sí mismo una distinción y se pone a sí mismo fuera de la mera vida biológica. De este modo, «hay política porque el hombre es el ser vivo que, en el lenguaje, separa la propia nuda vida y la opone a sí mismo, y, al mismo tiempo, se mantiene en relación con ella en una exclusión inclusiva» (Agamben, 2003: 18). Esto quiere decir, que para experimentarse políticamente sin dejar de ser viviente, el ser humano debe abandonar su relación a la mera vida, y en alguna medida negar la vida en él, pero esta misma negación supone que su cualidad de viviente se vuelve relevante políticamente, como su límite y, sólo en esa medida, como su condición de posibilidad. De esta manera, «la paradoja de la biopolítica [es] la necesidad en que se encuentra de someter a la vida misma a una incesante movilización» (Agamben, 2004: 187) al punto que «la política es ahora literalmente decisión sobre lo impolítico (la nuda vida)» (Agamben, 2004: 221).

Es por esto que la amenaza fundamental es el retorno de la violencia que lo político habría logrado neutralizar - -0 bien que se vuelva lo político mismo expresión de esa violencia-, el regreso entonces de la naturaleza y su pura fuerza ciega que arrasaría con la ciudad y su derecho a ser. Bajo este sino, el divorcio entre vida pública y vida privada ha devenido en una exilio de lo político y un ascenso de lo social que termina por hacer coincidir lo público y lo privado bajo una sola consigna: la necesidad del derecho como control de la violencia. Así, el propio derecho se vuelve la violencia legítima que detiene la violencia natural. En este sentido, «la política ha sufrido un eclipse duradero porque ha sido contaminada por el derecho, y se ha concebido a sí misma, en el mejor de los casos, como poder constituyente (es decir, violencia que establece el derecho), cuando no se reduce, simplemente, al poder de nego- 
ciar con el derecho. Pero, verdaderamente, política es sólo la acción que corta el nexo entre violencia y derecho» (Agamben, 2004: 127-128). Una acción que, si bien corta tal nexo, no logra jamás romperlo definitivamente. $\mathrm{Y}$ así parece que tuviésemos que resignarnos a que sea quizá la única ratio essendi de la política el domeñar la vida de los sujetos en su cuerpo y su pensamiento. Esta suerte de «heurística del terror» sui generis, es decir, esta validación de la necesidad de lo político como forma de control de la violencia originaria que amenaza con retornar, legitimaría el hecho que la política misma se haya vuelto dispositivo de control y de normalización, en el circuito inclusión/exclusión por el que la nuda vida se quiere ella misma comienzo y fin de lo político.

Ahora bien, ¿es cierto que la política se resume en este circuito de exclusión e inclusión? ¿Es cierto que esta metamorfosis de lo político es irreversible tal como lo defiende Agamben? Recordemos sus palabras: «Por eso la restauración de las categorías políticas clásicas propuesta por Leo Strauss y, en sentido diverso, por Hannah Arendt, no puede tener más que un sentido crítico. Desde los campos de concentración no hay retorno posible a la política clásica; en ellos ciudad y casa se han hecho indiscernibles y la posibilidad de distinguir entre nuestro cuerpo biológico y nuestro cuerpo político, entre lo que es incomunicable y queda mudo y lo que es comunicable y expresable, nos ha sido arrebatada de una vez por todas. Y no somos sólo, por emplear las palabras de Foucault, animales en cuya política está puesta en entredicho su vida de seres vivientes, sino también, a la inversa, ciudadanos en cuyo cuerpo natural está puesta en entredicho su propia vida política» (Agamben, 2003: 238). ¿Es cierto este dualismo? ¿Son ciertas sus consecuencias teóricas? ¿Es el biopoder un «nuevo Leviatán» y somos nosotros sólo la deriva entre la emancipación y el control?, ¿una deriva entre una liberación respecto del poder y un empoderamiento de nuestra animalidad, por ejemplo? Finalmente, y ahora circunscritos más directamente a nuestro asunto en este trabajo: ¿coincide este modelo de pensamiento, la biopolítica, con la expresión y el fondo del pensamiento político de Hannah Arendt? ¿Excede este último o no los márgenes del paradigma biopolítico? Eso es lo que revisaremos en adelante en este trabajo.

\section{Natalidad, espontaneidad y vida: ¿Una cuestión biopolítica?}

El propósito de este trabajo es determinar la quaestio iuris de una interpretación biopolítica del pensamiento de Hannah Arendt. Esta interpretación realiza una reapropiación en clave biopolítica de ciertos conceptos utilizados tanto temática como operativamente por Arendt, que son centrales a la arquitectónica interna de su filosofía política: poder, natalidad, vida, libertad, etc. El análisis de tales conceptos y su comprensión ulterior serán centrales entonces a la hora de intentar esclarecer los supuestos de dicha interpretación. Entre ellos, y por razones que más adelante se harán evidentes, es el concepto de «natalidad» el más relevante. Luego, si lo que se pretende es calibrar la pertinencia última de esta interpretación es necesario emprender, como primer paso en el análisis, el examen del concepto de natalidad arendtiano y, posteriormente, revisar su conexión con el planteo biopolítico, procurando detenernos con especial énfasis en un punto álgido, a saber, la imbricación entre natalidad $\mathrm{y}$ vida.

Esta prioridad metodológica es reforzada por el hecho que algunos comentaristas de Arendt han querido ver, desde el lazo entre natalidad y vida principal- 
mente, la posibilidad de una lectura biopolítica de Arendt que se articula en torno a alguno de los supuestos del concepto de natalidad o de sus pares. Al parecer, su convicción es que el concepto de natalidad arendtiano es él mismo biopolítico o bien constituye un soporte adecuado para tal entronque. Lo central de dichas lecturas ${ }^{1}$ parece ser el reconocimiento de una aparente imbricación entre vida, natalidad y política, a partir de bases teóricas sostenidas sobre el concepto de «biopoder» en las cuales parece poder quedar amparada una supeditación insuperable de la condición humana a la vida biológica que condicionaría la libertad como un factum «prepolítico».

Así ocurre, al menos en principio, con el punto de vista defendido por Miguel Vatter en su texto «Natality and Biopolitics» (Vatter, 2006), donde arguye que «Arendt favorece esta interpretación, al afirmar que la vida de la especie no conoce el nacimiento y la muerte [...], mientras que la vida humana empieza con el nacimiento y termina con la muerte. El proceso biológico en el hombre (...) [es] eternamente repetitivo» ( $\mathrm{HC} 98)$ mientras que la vida humana, en su linealidad, es una “"interrupción” del círculo natural de la vida» (Vatter, 2006: 146). Restringidos a este punto de vista, estaríamos obligados a admitir que en Arendt la vida humana no conseguiría ser más que interrupción del carácter cíclico de lo que, en principio, podemos entender aquí como «vida natural» en general o vida vegetativa: aquélla que el hombre comparte con el resto de los vivientes; de modo que esa vida, por su carácter primario, se impondría de antemano como un valor que hace de la humanidad sólo una «diferencia específica» más, respecto de un valor más general que es la vida en tanto tal y que operaría aquí como criterio rector último. Pero lo cierto es, sostendremos, que lo que intenta pensar
Arendt es más bien el límite de esta vida biológica, su desbordamiento, su excedencia.

Lo que intentaremos defender, entonces, con el objeto de circunscribir más precisamente lo que llamaremos el carácter «contra natura» de la natalidad y su lazo con la espontaneidad, es que precisamente por este carácter es que resulta en extremo problemático interpretar la «natalidad» en Arendt como un concepto biopolítico. Para afirmar esta dificultad es necesario defender que la natalidad se revela más bien como un concepto «contra-biológico», o «ultra-biológico», si se nos permite la paradoja. Ahora bien, es evidente que no se trata de caer nosotros también en el esquema dualista que estamos criticando (natural/contra-natural; biológico/político, etc.), pues eso acarrearía que esta contranaturalidad no fuese más que una absoluta autonomía de la natalidad respecto de su condicionalidad biológica. De lo que se trata más bien, a nuestro juicio, es de hacer convivir una triple condición fenomenológica de la natalidad, que la biopolítica inevitablemente desdibuja: Que la natalidad es un factum existencial, un régimen ontológico y una condición política.

Esto es así aun cuando la reivindicación de la natalidad como base de lo político en Arendt pueda legítimamente ser entendida como una respuesta a la producción sistemática ejercida por el totalitarismo de lo que ella misma ha llamado «mera existencia» (Arendt, 1968: 301) y aun cuando esta alienación última pueda, además, ser interpretada como reducción a la mera vida y el propio totalitarismo parezca quedar mentado allí como maximización del biopoder. Aun si esto así, todo ello no transforma el concepto de natalidad en un concepto biopolítico como si éste no fuera sino la contracara de esa reducción. Es más, aquello nos parece un ejemplo de metabasis allo genos 
en tanto oscurece la comprensión última del contenido fenomenológico de la natalidad en Arendt, haciendo suponer que ella no es más que una determinación de nuestro talante natural o biológico y que en tanto biológica sólo tiene consecuencias sobre lo político. Tal subrepción parece implicar que el concepto de natalidad en Arendt, y una reelaboración biopolítica de éste, arriesgan una descomposición de su sentido político.

Nuestra convicción se basa en que la separación entre zoe y bios - o lo que Arendt llamó, como dijimos, «mera existencia» versus la «vida política» o cualificada - no podría suponer, ni siquiera por abstracción, la reconducción del bios politikos a la zoe, más bien, al contrario, la transformación de la vida política en mera vida, operada por el totalitarismo, es una trasgresión de la condición humana no por reducción a su mera posición elemental, sino por vía de una perversión irreversible. La «mera vida» no es la pulsión última a que queda reducida la vida política que deja de ser tal, al ser violentada hasta el extremo y anulada en su unicidad, es más bien su completa subversión. Lo que queda tras ella, entonces, no puede ser interpretado ni como menos humano ni como pre-humano. Ahora bien, para Vatter, la natalidad es primera, sobrevive y permanece inalienable, lo que es cierto, pero esto es así, creemos, no porque ella sea de suyo prepolítica y se perpetúe como fuente de una «mera vida» que más tarde puede cada vez volverse o no política. Ella es primera, nos parece, porque hace sobrevivir y perdurar la espontaneidad, una posibilidad que resiste y que sólo tiene sentido entonces en el mundo humano, aun cuando lo humano de la vida parezca desaparecer en manos de la violencia totalitaria extrema.

He aquí lo que parece cuestionable de esta recepción de Vatter: La disyunción artificial que establece por vía de la reconversión de la natalidad al sustrato de la vida biológica, al señalar que el concepto de natalidad en Arendt, entendido como quiebra de la vida, «hace posible el paso de la vida como "objeto de poder" a la vida como "sujeto de la libertad"» (Vatter, 2006: 146). Esto es impreciso, a nuestro juicio, porque lo que defiende Arendt al hablar de la «mera existencia» de quien padece la violencia totalitaria es la imposibilidad de que la vida humana sea ya inteligible cuando queda desprovista de un sujeto que la haga suya. Así, no se trata de que la vida tout court permanezca inalienable cuando el viviente, sólo hasta allí aparentemente humano, es reducido a puro despojo de sí por la experiencia del totalitarismo, y que lo que allí todavía sea defendible o lo que haga todavía político, o mejor, digno de derechos políticos, a ese infrahombre, sea la vida en general que subyace en él. Entonces, por una parte, ni la vida puede ser «objeto de poder», pues los que padecen la dominación serán siempre los hombres, no en tanto meros vivientes, sino en tanto hombresen-plural histórica y culturalmente dados, ni la vida puede, por otra parte, ser «sujeto de libertad», puesto que la libertad es una experiencia únicamente humana posibilitada por la acción y su espontaneidad.

Que la humanidad del hombre esté puesta en cuestión y corra el riesgo de desaparecer por el poder de aniquilación del totalitarismo significa, entonces, que lo que con él se aliena y desaparece no es la vida de los hombres sino el espacio interhumano, el mundo, en sentido fuerte, que excede necesariamente el orden biológico. Por eso lo biológico no puede ser ni el residuo de nuestra humanidad, ni el principio de nuestra libertad. Pero precisemos la tesis que nos parece más problemática en Vatter, es ésta: «Arendt insiste repetidamente en que la natalidad no sólo 
es la que "inserta" la vida individual en un mundo ya establecido, sino además es la que "renueva" al mundo mismo que, de otra forma, perecería junto con la muerte de los individuos. Pero esto es precisamente afirmar que la natalidad es irreductible al bios politikos: Ella antecede esencialmente al mundo común. Para comprender su significado uno debe retrotraer la natalidad al nivel de la zoe y preguntarse qué diferencia introduce la natalidad en y para la vida biológica (zoe). En suma, si en Arendt existe una concepción "positiva" de la biopolítica, ella depende de concebir la natalidad como una politización de la zoe, no del bios» (Vatter, 2006: 152). Pero, repliquemos, la distinción entre zoe y bios no es sólo la distinción entre la vida de la especie y la vida del individuo, entre el movimiento que va desde la génesis y la corrupción, que preside el ciclo de lo natural, hasta la distinción que «el cada cual»» de todo individuo encuentra en la singularización que representa su ser frente a la comunidad de la forma que irremisiblemente comparte. Más bien, y por eso este tránsito es asunto sólo de los hombres, de lo que precisamente se trata con esta distinción es que esa singularidad que le es propia a cada hombre en tanto individuo se realiza como acción y no como movimiento, esto es, que la singularidad que pone cada humano de manifiesto no es sólo la individuación de su alteridad relativa respecto de una especie, sino la unicidad absoluta que supone su diferencia sin comunidad de género.

Es precisamente esto lo que contradice la llamada «politización de la zoe» a la que Vatter apela, pues en Arendt no se trataría con esto de la «retrotracción de la natalidad al nivel de la zoe», de la diferencia que introduciría la natalidad en $y$ para la vida biológica, sino más bien de que la vida biológica no sólo es trasgredida e interrumpida por el bios politikos, sino que por la natalidad, la vida biológica es trascendida, y de un modo irreversible. Así, en Vatter la apelación a una politización de la labor y del trabajo no parece más que la negación de la autonomía última de la esfera de los asuntos humanos y de la realidad nueva que ella engendra, más allá de los condicionamientos externos que el habitar humano encuentra o se impone a sí mismo por su especificidad.

Refuerza lo antes dicho el que Arendt sostenga en La condición humana que, si bien la natalidad es la precondición de la existencia humana, ella nunca conseguiría «explicar lo que somos o responder a la pregunta acerca de quiénes somos por la simple razón de que ella nunca nos condiciona absolutamente» (Arendt, 1993: 246). Para Arendt, con la natalidad se trata cada vez de la posibilidad de lo nuevo, que no puede subordinarse a ningún automatismo, pues «sin la acción para hacer entrar en el juego del mundo el nuevo comienzo de que es capaz todo hombre por el hecho de nacer, "no hay nada nuevo bajo el sol"» (Arendt, 1993: 227). Lo que aparece como siempre nuevo e impredecible, además de la acción que cada hombre pone en juego en virtud de su carácter de ser natal, es el sí mismo que con la acción cada vez confirma y/o desmiente aquella historia suya siempre de camino, por decirlo así, hacia la configuración de un quién que no acaba de narrarse y descifrarse sino con la muerte. Es por eso que, por otra parte, resulta impropio interpretar el permanente influjo e interrupción de la acción como expresión de nuestra libertad contra la regularidad de lo natural o como un mero suspenso de aquella legalidad, y menos aún como otro tipo de regularidad análogamente automática. Sin embargo, no es sino esto lo que defiende Vatter, al decir que «la capacidad de iniciar una nueva serie de eventos tiene un "automatismo" que es análo- 
go al automatismo de un proceso natural, pero se diferencia de éste en el sentido de que la libertad es el automatismo de la interrupción de los procesos naturales» (Vatter, 2006: 153). Si así fuera la espontaneidad de la acción quedaría desmentida en su imprevisibilidad y autonomía. Es claro para nosotros que la libertad en Arendt no podría agotarse en una mera emancipación de la necesidad ni en la interrupción de procesos naturales.

Esta unicidad y este carácter sui generis no sólo es la característica privativa de la acción de los hombres, que se distinguen y religan por ella, es también propia del espacio que recíprocamente generan como «trama» de relaciones, y su contexto es siempre el de la permanente reapropiación de un espacio común —no de cosas, sino de acciones y palabras que tienen como atributo la libertad, novedad y contingencia - que surge y se limita por su interacción. Tal espacio no se deduce de ninguna comunidad natural, ni física; más bien, «el físico y mundano en-medio-de, junto con sus intereses, queda puesto bajo, y por así decir, sobrecrecido por otro en-medio-de absolutamente distinto, formado por hechos y palabras y cuyo origen lo debe de manera exclusiva a que los hombres actúan y hablan unos para otros. Este segundo, subjetivo en-medio-de no es tangible, puesto que no hay objetos tangibles en los que pueda solidificarse; el proceso de actuar y hablar puede no dejar tras sí ni resultados ni productos finales. Sin embargo, a pesar de su intangibilidad, este en-medio-de no es menos real que el mundo de cosas que visiblemente tenemos en común» (Arendt, 1993: 207). Su realidad sui generis supone entonces que no se trata con él de un mero modo-de-ser compartido, sino de una actividad, una performatividad, que es cooriginaria a la pluralidad y natalidad de las cuales arranca su moción.
3. Natalidad y unicidad: más acá de lo político y más allá de lo biológico

La propia natalidad es ella misma doble en su capacidad de volver todo inicio humano posible, y así, están relacionados a ella dos principios primeros. Como lo afirma Peg Birmingham en su ensayo «The an-archic event of natality»: «el principio (arché) de este acontecimiento es doble: el principio de publicidad y el principio de donación» (Birmingham, 2007: 766). Ahora bien, la asunción de este distingo supone retrotraer la natalidad - el hecho de ser los hombres seres nacientes y en cuanto nacientes iniciantes - a la posibilidad de entrar en un mundo que nos precede en el tiempo y en el espacio, pero que está condicionado en su posibilidad y duración, por el hecho que quienes llegan a él son vehículos de la novedad y contingencia que hacen permanecer a este espacio como mundo y como mundo humano. Traídos a él y modificados por él, somos también sus artífices y sus garantes. El mundo, tanto como mundo vital, como mundo de objetos, y como mundo de sentido, es ininteligible mientras no es leído como hechura humana y como inscripción de lo humano en lo vital, como transitividad de lo humano más allá de sí. Es por esto que ese mismo mundo comparte una fragilidad idéntica y proporcional con la de aquellos que lo colman, nutren y sostienen, con aquellos que lo ponen en obra por el mero hecho de la contigüidad humana (cfr. Arendt, 1993: 204).

Es, además, por esta razón que Arendt insiste, una y otra vez, en el hecho que «la fragilidad de [...] todas las materias que atañen a los hombres que viven juntos, surge de la condición humana de la natalidad y es independiente de la fragilidad de la condición humana» (Arendt, 1993: 214). El espacio interhumano está atravesado por la misma contingencia y 
afectividad que la que cada uno de sus miembros padece por el hecho de tener también su origen en la natalidad. Por otra parte, la publicidad que entraña la natalidad como initium estriba en una cierta solidaridad que inaugura - sin garantía de naturaleza humana alguna, de ninguna ley moral o reino de los fines, de ningún principio altruista, biológico $\mathrm{o}$ metafísico, de ninguna comunidad natural o pacto social alguno- - y que da testimonio de la interdependencia humana. Es claro que para Arendt lo que sostiene la fragilidad del lazo interhumano es la posibilidad de una confianza recíproca que no tiene más fundamento que su propio darse; así, comentando a Agustín, Arendt enfatiza tempranamente el hecho que «esta interdependencia se pone de manifiesto en el mutuo dar y recibir en el que consiste la convivencia de la gente. La conducta de unos individuos para con otros se caracteriza aquí por un creer o confiar (credere), que se opone a todo conocimiento real o potencial. Todo lo histórico, o sea, todos los acontecimientos humanos y temporales, se captan por medio de este "creer" que es también un "confiar en", y nunca por medio de un comprender (intelligere). Esta fe en el otro es la fe en un futuro común que habrá de verificarse después. [...] el creer que surge de nuestra mutua dependencia precede a toda posible verificación» (Arendt, 2001: 136).

Ahora bien, que la natalidad suponga «un principio de donación» (giveness), un «principio de lo dado», y no sólo publicidad, significa, lo hemos dicho, que lo que precede al hombre políticamente investido no es una pura materialidad, una existencia desnuda o privada de cualidad. Eso dado no es la pura singularidad individual más que por abstracción, lo que esa positividad nombra más bien es $a b$ initio la pluralidad de esas singularidades que convergen y de cuya distinción es condición. Arendt defiende en Los orígenes del totalitarismo que «con esta mera existencia, es decir, todo lo que nos está misteriosamente dado por el nacimiento y que incluye la forma de nuestros cuerpos y los talentos de nuestras mentes, solamente puede tratarse adecuadamente por medio de los impredecibles azares de la amistad y la compasión, o por medio de la gran e incalculable gracia del amor, que dice, con Agustín, "Volo ut sis" (Quiero que seas) sin ser capaz de dar ninguna razón en particular para tal afirmación suprema e irremontable (Arendt, 1968: 301)».

Pero lo que quiere aquí establecer Arendt, creemos, no es, y esto contra Birmingham, que la singularidad de la vida individual, privada de cualidad, se oponga a la pluralidad como su antítesis dialéctica o material, que la vida privada de cualidad sea una vida pre-política o anti-política, ni menos que ella entrañe por sí misma, en la ausencia efectiva de derechos, un «principio de fundamentación ontológica de lo político». Desde esta perspectiva, tampoco se trata de que «los principia del inicio y los principia de lo dado [...], supon[gan] una relación diferente: el primero una relación a la pluralidad, el segundo a la unicidad y a la singularidad...) (Birmingham, 2007: 766), en sentido estricto. Ni menos aún que sea ésta «una relación de disyunción entre la apariencia única de lo singular y esta pluralidad». Aun cuando existe una «estratificación del acontecimiento originario de natalidad [que] complica y vuelve imposible el intento por establecer una identidad fuera de esta pluralidad» (Birmingham, 2007: 774), la singularidad y unicidad, aquí mentadas, no son el correlato de una suerte de comunidad natural, prepolítica, pero sin embargo, virtualmente política. La vida privada de cualidad no es auténtica unicidad y su singularidad es, en su privación, si es tal, no 
ausencia de naturaleza o de cualidad política, sino ausencia de un sentido de lo político y del espacio para éste.

La alteridad que subraya esta vida privada de cualidad, todavía una, no es ni origen primordial ni privación escatológica, su «inhumanidad» no es la inhumanidad de lo pre-humano o cuasi-humano, sino sólo facticidad y materialidad muda. $\mathrm{Su}$ singularidad no tiene una comunidad natural como origen, ni una comunidad política como destino. Esto puede hacerse más claro recurriendo al siguiente texto de Arendt: «El "ser-otro-que" — dice Arendt-, la alteridad misma, tal como ella es dada en todas las cosas, sólo indica la pluralidad. El hecho que yo pueda realizar esta alteridad, siendo conmigo mismo, es la condición de posibilidad para que yo pueda ser otro entre los otros [...]. La singular paradoja consiste en que el elemento esencial del "unus" no puede jamás realizarse en el hecho de ser solo, sino solamente con los otros; en que, por ser efectivamente uno, yo tengo necesidad de todos los otros; y lo que era el elemento esencial del Alter no puede realizarse, a la inversa, sino en el hecho de estar solo, a saber, "to be by myself". En este sentido, es la soledad la que es condición de posibilidad de la comunidad, y jamás a la inversa, y es la comunidad la que es condición de posibilidad del ser-uno» (Arendt, 2002: 289). Es necesario insistir, entonces, en la diferencia entre la alteridad relativa de la singularidad y la alteridad absoluta de la unicidad; y es también necesario reafirmar el estatuto ontológico del concepto de «pluralidad» versus la acepción estrictamente política de «comunidad». No hay comunidad de singularidades, sino de hombres: la pluralidad es «pura contigüidad humana» de unicidades, no meramente de seres singulares. Sólo la unicidad puede ser «sujeto», la singularidad, en cambio, sólo puede ser atributo de un sujeto, pero nunca sujeto ella misma. La pluralidad es condición de la unicidad, que no es sólo la del uno-entre-los-otros, sino también, y antes, la del uno-para-si-mismo. Esto, pues la pluralidad no es sólo un factum existencial sino también un hecho de la vida del espíritu.

Pero volvamos al texto donde Arendt introduce esta idea de lo «dado». Eso que (quid) somos antes de quienes (qui) somos, o mejor el mero hecho de que somos (quod), es decir, la positividad de nuestro cuerpo, y la capacidad virtual de nuestra mente y sus talentos, no es tanto un dato de nuestra unicidad como un hecho de nuestra facticidad y finitud. Tal como aclara Arendt: «no se debe confundir la singularidad con la unicidad y el carácter excepcional-único propio de todo individuo particular. La unicidad es precisamente política y ella se evanesce en la singularidad en la cual no tenemos ya a nadie por relación a quien distinguirnos y con quien arriesgar ser confundidos»» (Arendt, 2002: 499). Es ésta indistinción lo que caracteriza aquella «mera existencia» que Arendt mienta en Los orígenes del totalitarismo. Pero que el trato de tal facticidad primaria sólo pueda librarse a «los impredecibles azares de la amistad y la simpatía, o a la gran e incalculable gracia del amor»(Arendt, 1951: 301), no sólo significa que ella está desprovista de mundo y de comunidad, significa también que - tanto respecto de la positividad del devenir como de la del hombre mismo - la ausencia de deber respecto de ambos, la ausencia de un lazo moral o espiritual previo a su contingencia, no anula su carácter de «dato», o si se quiere, de misterio. Misterio éste que no se resuelve ni en aparición ni en apariencia, que está más allá de lo privado y de lo público, lo lógico o lo ontológico, sino que supone además lo previo al sentido, al dominio y a lo inteligible, lo inefable, esto es, el acontecimiento. 
Es a esto, a nuestro juicio, a lo que apunta principalmente Arendt con esta idea de lo «dado» en nosotros y lo dado en general, a saber, a lo que nos antecede y no podemos modificar, ya sea porque irrumpe en lo real sin nuestro concurso, ya sea porque es precisamente lo que hay de real en nosotros más allá de nuestra iniciativa. Es esta relación entre lo dado y el acontecimiento la que, nos parece, le pasa desapercibida a Peg Birmingham. Ahora bien, aun cuando ella tiene razón en insistir en el hecho que con la natalidad «Arendt apunta probablemente a la reflexión agustiniana de que el acontecimiento de la natalidad habla sobre lo que está dado — de hecho, misteriosamente dado - y que no puede cambiarse» (Birmingham, 2007: 766), esto no significa que el misterio de lo dado aluda sólo a lo que la natalidad tiene de material o biológico o lo que viene dado en ella por ese sustrato, ni tampoco a lo que en la vida «resiste» como mera existencia. Dicho misterio alude antes a la natalidad como vehículo del acontecimiento desde tal facticidad, y con ello a la capacidad misma de la espontaneidad pura, que puede, al devenir acción, inaugurar algo completamente nuevo e impredecible frente a lo inexorable. Por otra parte, y esto es fundamental, que la acción no tenga un autor, un dueño último capaz de predecirla en sus motivos y controlarla en sus efectos, supone de suyo que ella es también, a su modo, acontecimiento. El acontecimiento, en su pura gratuidad, no es entonces un puro fatum, él reúne lo nuevo y lo irreversible, lo que está en nuestro poder iniciar, y aquello que nos trasciende irremisiblemente.

$\mathrm{Y}$ es por esto, que Arendt toma prestadas, secularizándolas, las categorías de creación y creaturalidad para interpretar la puesta en el mundo del fenómeno humano, y es por esto también que concede un carácter «sagrado» a la espontaneidad humana. La vida desnuda si bien es vida privada de cualidad, es también ya espontaneidad, a saber, espontaneidad sin agente, espontaneidad pura, no de la razón, sino para la acción. Arendt asegura por esto que: «El inicio ha hecho su aparición en el mundo con el hombre. Es sobre esto que reposa el carácter sagrado de la espontaneidad humana. La exterminación totalitaria del hombre en tanto que el hombre es la exterminación de su espontaneidad. Lo que equivale simultáneamente a la anulación de la creación en tanto que creación, en tanto que haber-instaurado-un-comienzo.» (Arendt, 2002: 82-83).

Es esta afirmación de la existencia en su puro darse, lo que corresponde al sentido más propio que Arendt parece reconocer en el Volo ut sis agustiniano. Así, la «gracia» del amor con la que puede tratarse con lo misteriosamente dado en nosotros - es decir, con esa pura facticidad de nuestra existencia, revelada como «gratuito don que no procede de ninguna parte» (Arendt, 1993: 15) — es ya la figura de una respuesta a ese don. Don que, sin embargo, da cuenta de la pasividad irrebasable del existente, atravesado por esa relación en que acción y acontecimiento nombran los límites del fenómeno humano mismo. Arendt comenta en su Diario: «la fuente de la libertad, que se expresa por la espontaneidad [...] es el acontecimiento. Es éste quien procura [...] a la libertad, el material a partir del cual sólo la espontaneidad puede inflamarse. Es solamente en el acontecimiento mismo [...] que se toman las escasas decisiones fundamentales de las cuales yo sé que son libres, por el hecho que no puedo revocarlas». (Arendt, 2002: 113). De ahí que la libertad no nombre sólo la indeterminación de la facticidad ni el acontecimiento nombre sólo el hecho de la vida desnuda. La espontaneidad es ocasión de lo nuevo y lo nuevo es el sello de lo libre. 


\section{Libertad y mundo: A propósito de Kant}

Arendt comenta en su diario a propósito de la relación entre libertad y acción: «En la libertad de la espontaneidad, que consiste en "iniciar una serie a partir de sí-mismo", el hombre es único y su obra, en tanto que ella es creación, le da alas. En la acción, sometida a la exigencia de justicia, y constantemente tentada de liberarse por la violencia del constreñimiento de las necesidades, el hombre está en compañía de otros del lado de la responsabilidad política» (Arendt, 2002: 226-227). Esta «libertad de» sui generis, contraria hasta cierto punto a la libertad de la espontaneidad, es ya un principio de autonomía, no en el sentido de la autonomía kantiana, sino más bien, como una libertad que está asociada a la paradójica imposibilidad de escapar a la responsabilidad de la acción y a la iniciativa que ella vehicula. Hemos de estar dispuestos a pagar el «precio de la contingencia por haber recibido el regalo de la libertad»» (Arendt, 1984: 472), y al mismo tiempo hemos de asumir que la libertad que la acción vuelve posible es una libertad no de un sujeto soberano, sino una libertad-sin-soberanía que antes que ser una libertad desde sí es más bien una manera de ser entre-otros, una libertad que tiene como condición y límite a los otros. Pero la espontaneidad no es mera espontaneidad de la razón, es también condición de la acción, y del poder como acción concertada.

Ahora bien, lo anterior justifica el hecho que no sea la libertad de la espontaneidad sino la del libre arbitrio ${ }^{2}$ la que es interpretada por Arendt como una perversión de la libertad política original, efectivamente mundana, marcada por el tránsito desde una experiencia de esa libertad, pública, política, hacia más bien una mera representación de la libertad, siempre in- terna, individual y muda. Se trata aquí de la brecha que va de la libertad política a la libertad filosófica. Pero así como no existe un sentido previo o independiente del mundo común, tampoco existe estrictamente una libertad interior e individual, ni siquiera un sentido, individual o privado. Y con esto llegamos a un punto central: Creemos que al reivindicar la espontaneidad como el concepto que permanece irreductible en nuestra representación de la libertad, es posible distinguir entre la libertad práctica y la libertad trascendental y restringir a esta última, a pesar de las apariencias, el contenido legítimo de la libertad intramundana que Arendt reconoce y legitima como ineliminable. Volvamos entonces a este asunto, esta vez para defender la necesidad de afirmar la centralidad de la matriz kantiana en la forja del concepto de libertad arendtiano.

Hagamos esto retomando nuestra discusión con Vatter. Él distingue tres rasgos fundamentales de la libertad en Arendt, que podríamos resumir así: a) la libertad es espontaneidad, como capacidad de interrumpir el automatismo de la naturaleza; b) la libertad es condicionada, y su condición es la natalidad, ella es intramundana; c) la libertad es liberación respecto de la vida biológica (Vatter, 2006: 152-157). A juicio de Vatter, de estos rasgos el primero sería kantiano y el tercero agustiniano, mientras que el segundo rasgo no estaría particularmente asociado a ningún autor. Lo que intentaremos mostrar a partir de este desglose, es, primero, cómo tales rasgos han sido formulados de modo equívoco en sus presupuestos y, en segundo lugar, cómo el concepto de libertad como espontaneidad, que es considerado por Vatter como secundario, es especialmente gravitante para cifrar la especificidad y peculiaridad de la idea de libertad arendtiana.

Ahora bien, quizá convenga comenzar preguntándonos respecto de esta pri- 
mera definición de la «libertad como espontaneidad», en qué sentido podría, kantianamente hablando, ser considerada como «el automatismo de la interrupción de los procesos naturales» (Arendt, 1993: 153). Arendt, sin duda, habla de un automatismo de esta espontaneidad de la acción, análogo al automatismo que rige la causalidad natural, pero esta analogía no supone que la espontaneidad puede ser definida sólo como el "automatismo» de esa interrupción. Lo que Arendt privilegia al establecer que «a la acción [...] le es peculiar sentar un nuevo comienzo, empezar algo nuevo, tomar la iniciativa o, hablando kantianamente, iniciar por sí-mismo una cadena» (Arendt, 2005: 113) es, más bien, que la posibilidad de la interrupción supone otra posibilidad, la de una «causalidad» independiente de la natural, es decir, que la acción origina, a partir de sí misma, una capacidad que puede ocasionar no sólo la interrupción, sino la discontinuidad radical de los procesos naturales, en otras palabras, que la acción puede suspender o incluso volver irreconocible el desenlace de un proceso natural, dicho secamente que la acción puede ocurrir a expensas del mundo fenoménico y su legalidad, hablando kantianamente. Lo que Arendt entiende al decir que «el milagro de la libertad yace en este poder-iniciar» es precisamente que este pathos del inicio es independencia y separación de toda causalidad.

Así como la acción puede subvertir, para decirlo gravemente, la naturaleza y la historia, del mismo modo, «aun cuando el terror [...] permite a la fuerza de la naturaleza o de la historia moverse libremente a través de la especie humana» (Arendt, 1951: 461), siempre cabe todavía ante tales fuerzas la limitación que origina la acción. Pues, que el terror pueda volver tales poderes - la naturaleza y la historia - ilimitados e ilimitables, obedece a que la acción se ha vuelto estéril para producir la limitación que, sin embargo, está siempre en su poder. Sólo por esto la fuerza de tales extremos permanece «sin ser limitada por ninguna acción humana espontánea» (Arendt, 1951: 465). Tal fatalidad no ocurre por un suprapoder de la naturaleza y de la historia que se vuelva inexorable, sino por una impotencia de la acción que ya no tiene capacidad para concertar y para humanizar el espacio donde un poder interhumano sea posible. Es en este sentido que Arendt insiste en que la violencia no puede devenir sustituto del poder auténtico.

$\mathrm{Y}$ es por esto que para Arendt, como asegura Jacobitti, siempre «los individuos a través de la acción, pueden hacer una diferencia en el mundo; lo que muestra que ellos no están completamente indefensos frente a las fuerzas económicas, sociales e históricas» (Jacobitti, 1988: 65). Así, el antídoto para estas fuerzas y su inconmensurable potencia es precisamente la acción. Y es por esto que Arendt considera la acción bajo el símil del milagro hasta, como afirma Jacobitti, llegar a «considerar la capacidad humana para la acción como inexplicable, literalmente milagrosa» (ibidem). Esta ausencia de explicación no obedece tanto al aparente ex nihilo del cual la acción surgiría, como a la realidad completamente nueva que ella produce. En este mismo sentido es que Kant destacaba la necesidad de pensar una causalidad libre, una causalidad que desde sí pudiera fundar un curso nuevo de acciones con sus propias consecuencias fenoménicas en el mundo.

Por otra parte, para Arendt, no es la «fecundidad» de la vida la que ha sido previamente singularizada mediante el nacimiento. Y menos aún, ocurre que ella «opon[ga] la natalidad como la singularización automática de la vida» (Vatter, 2006: 154). La natalidad en Arendt es sobre todo "segundo nacimiento», nacimiento a un espacio nuevo, pero también 
a un mundo ya constituido, dotado de un sentido humano, que si bien es suspenso y hasta cierto punto negación del mundo natural, es también correlato de una inmediatez de esta consciencia de sí como consciencia de su facticidad, y, paralelamente, como consciencia del poder de iniciar que, paradojalmente, la finitud de este poder trae aparejada. El mundo opuesto al mundo dado que el hombre funda por la acción no es sólo «emancipación de la naturaleza», sino contra-naturaleza, si se quiere. Y esto, como Arendt destaca estaba ya prefigurado en Kant, para el cual «la causalidad conquistada por el hombre [...] actúa en el seno de una causalidad de la naturaleza que le es por principio extraña, que desnaturaliza toda acción y que frustra toda realización. Pero, por el hecho que Kant plantea aquí a los hombres, es decir, la humanidad, en lugar del hombre, indica la posibilidad de un mundo opuesto al mundo dado. No es el hombre sino los hombres los que no son de este mundo - y que son capaces de erigir su propio mundo "moral" en y contra el mundo» (Arendt, 2002: 159). La vida humana como vida en común no es alienación del mundo natural, es autonomía respecto de sus automatismos.

Entonces, que «la natalidad gener[e] individuos completamente únicos y singulares, y [que] estas individualidades $\mathrm{s}$ [ea]n ellas mismas iniciantes», no significa que ellas sean «orígenes de interrupciones espontáneas del comportamiento uniforme» (Vatter, 2006: 154). Si bien es cierto que «la libertad no está condicionada por nada natural», esto no supone que por el hecho de ser la libertad una condición incondicionada deba ella ser literalmente interpretada como «[...] una idea o hecho de razón, y [que] según esto está radicalmente separada de la esfera de la vida». (Ibidem). La libertad como espontaneidad puede ser noumenal aquí sin contradicción, pero no porque sea una mera representación pensable, pero incognoscible, es decir, que no tiene objeto en una experiencia posible, y que permanece como idea pura de la razón. En la medida que con Arendt se trata de la libertad y espontaneidad de la acción y no de la razón ni del arbitrio, no hay nada más cierto para Arendt que «ya que el mundo hecho por el hombre no es el escenario de la acción y de la palabra [...] la libertad no tiene una realidad mundana»" (Arendt, 1996: 160) y entonces la libertad no puede ser un objeto, ni de la naturaleza ni de la razón, y, a la vez, no puede aparecer en el mundo de la vida, ni en el mundo de los útiles, sino sólo en el mundo del sentido, donde es imposible a los hombres concebirse a sí-mismos, al actuar, como no libres.

La acción es testimonio paradojal de la libertad, como dijimos, porque se trata de una libertad que no aparece a ninguna interioridad, ni se impone como atributo de ninguna naturaleza, ella es sui generis porque sólo aparece, para decirlo con Kant, en un Geistreich, en un «reino de espíritus», o con Arendt, en una comunidad de unicidades, una comunidad política. Es por esto que Vatter se equivoca al decir en relación a los hombres que «su libertad necesita ser una condición condicionada y que no sea ya meramente un objeto, una parte de la naturaleza», pues si bien la libertad debe ser, sobre todo, una «experiencia», vital, fáctica, empírica, su constatación, sin embargo, y volviendo con esto a Kant, no está dada en una percepción o apercepción, efectiva o posible, sino que se manifiesta si se acepta la paradoja como «fenomenalizable más allá del fenómeno», i.e., en la praxis. Esto puede ser explicado recurriendo al concepto kantiano de «realización noumenal» ${ }^{3}$, a saber, aquella capacidad de volverse práctica la libertad de la voluntad, en la medida que acarrea la posibili- 
dad de la posición de fines en un mundo opuesto al mundo dado. Es así como la libertad trascendental y su espontaneidad pueden volverse prácticas y quizá aun políticas. La libertad puede ser una experiencia sin circunscribirse a los límites de la experiencia.

Por otra parte, si bien uno de los sentidos de la libertad kantiana es el ser una idea bajo la cual actuamos, esto no significa que ella permanezca como meramente pensada, y entonces, que tal como Vatter argumenta, fuese cierto que «si fuese meramente pensada no podría ser "política", i.e., no podría tener "sentido", no podría tener fenomenalidad (para Kant, la libertad es un hecho de razón que no tiene fenomenalidad)» (Vatter, 2006: 155). Pero precisamente porque es pensada, es que la libertad puede volverse práctica y política. Es una necesidad básica de nuestro ser práctico «pensarnos» como seres libres. Ahora bien, la libertad no se agota en el como si desde el cual concebirnos; ella se realiza para Arendt intersubjetivamente, esto es, por la acción. La libertad kantiana de la razón se transforma en espontaneidad de la acción política en Arendt. Si la libertad en Kant es la ratio essendi de la ley moral y ésta la ratio cognoscendi de la libertad; en el caso de Arendt, la acción política y su trascendencia es la ratio cognoscendi de la libertad y la libertad su única ratio essendi.

Ahora bien, la facticidad que se expresa en la libertad como espontaneidad estriba en el hecho de estar ligada a una suerte de pasado inmemorial, es decir, a nuestra imposibilidad de ser conscientes y contemporáneos respecto de nuestro propio origen, he ahí su carácter inverificable; y aún más, al hecho de estar dado este origen previamente a su sujeto, por así decirlo. Sólo en este sentido, es necesario «privar a la libertad de su incondicionalidad condicionándola a la natali- dad» (ibídem), en la medida que «la acción sólo puede ser la intensificación de la natalidad» (ibíd.). De este modo, dice Vatter, «la natalidad, la condición de la vida humana, está a su vez condicionada por un acto de creación divina [...]. El punto de Arendt aquí parece ser más bien que Dios crea la especie humana de forma que la vida pueda tener un comienzo (i.e., la natalidad) y ser en torno a dicho comienzo (i.e., en el sentido de que los hombres responden a su condición de la natalidad e intensifican tal condición mediante la acción...) [...] -Pero luego se pregunta-, "¿Qué es lo creado con el hombre? Esto es la facultad de iniciar, su creatividad, que está garantizada por su ser-creado: ¿Pero es su humanidad la que es creada? ¿O es su vida biológica? Ninguna, la creación del hombre da a la vida natural su libertad"» (Vatter, 2006: 156). Ahora bien, lo problemático, a nuestro juicio, es la conclusión que se sigue de este argumento, a saber, que, según Vatter, «la creación del hombre, entonces, se debe entender exclusivamente en función de la emancipación de la naturaleza» ( $i b i$ dem), sobre todo, al considerar que «la referencia a la creación divina en Arendt indica ese origen hacia el cual la natalidad extrae la vida (bios) fuera de la vida (zoe) para lanzarla dentro del mundo, pero no sin antes haberla singularizado»» (Vatter, 2006: 157).

Pero, ¿es tan claro que la vida humana en tanto creaturalidad obligue a entender la natalidad como, podríamos decir, mera salida de la zoe hacia un bios que además es sólo mundanización y singularización de la zoe, es decir, que se trate aquí de la restricción de la vida biológica por la asunción de una mundanidad? Finalmente, ¿es que acaso la libertad está salvada sólo por la liberación respecto de la vida biológica? Vatter comenta: «la natalidad, que da nacimiento a los seres singulares, es la libertad respecto de la vida 
biológica. La acción política, en la medida que intensifica la condición de la natalidad, debe ser entendida exclusivamente en términos de liberación respecto de la vida». ¿Es decir que, hablando a la usanza heideggeriana, la vida/ser se quiere en el hombre vida autopuesta, y con ello de algún modo no-vida, es decir, que ella pone al hombre fuera de sí misma precisamente para hacer de él diferencia de la vida? Luego, ¿no sería el hombre, contra Agamben, el que se pone asimismo fuera de la vida sino ella quién lo expulsa de sí para recuperarlo para sí y así recuperar-se? Ulteriormente, ¿en qué sentido ha de poder admitirse, que la acción política, en la medida que intensifica la condición de la natalidad, «ha de ser entendida exclusivamente en términos de la liberación respecto de la vida?» (ibidem), sobre todo, ¿en qué medida una liberación tal, definitiva por así decirlo, puede ser siquiera concebible?

$\mathrm{Y}$ es aquí donde se hace de nuevo pertinente volver sobre la metafórica teológica de Arendt en torno al par conceptual creación/redención. No es posible, creemos, admitir que el recurso a la idea de creación sea en Arendt la postulación de una teología (bio)política, pues con ello no se trata de otra cosa que de afirmar la necesidad de dar prueba de una facticidad que, no es ganancia de una vida humana dueña de sí misma, i.e., autoproducida, sino an-arquía de lo originado sin origen. El esfuerzo de Arendt se orienta a hacer admisible la idea de que la vida humana es una que carece de fundamento, que se padece a sí misma y a su propia finitud, pero que, y más importante, no encuentra en esta pura afirmativa la única clave hermenéutica de sí, pues en la medida que tal pathos supone tanto el reconocimiento de que ella está meramente dada, como también que su darse está mediado por la situación sui generis de ser ella previa a sí misma, en un origen antes del origen, un «pasado inmemorial», dicho levinasianamente, al que ella no puede acceder ni puede recuperar. Un origen entonces que si bien no es incondicionado, es fuente de un poder: su facultad de iniciar. Es por estas razones que resulta imposible admitir la legitimidad de una pregunta como la hecha a continuación por Vatter, a saber, «¿cuál es la evidencia fenomenológica de que el hecho de haber nacido, la condición de la natalidad, revele el carácter de criatura del hombre, i.e., su ser creado y, por lo tanto, demuestre la existencia de un Creador?» (Vatter, 2006: 158). La paradoja, no visible a Vatter aquí, es que este carácter de yecta en la existencia que exhibe la vida humana supone que ella no es origen de sí misma, pero, al mismo tiempo, que no hay para ella ningún fundamento original exterior a su propia constitución y a los condicionamientos que ella misma forja.

¿En qué sentido podría entonces desprenderse de este esquema especulativo de la creaturalidad, forjado precisamente para resignificar la analítica existencial y la finitud que le es propia, una «prueba» acerca de este origen o, menos aún, de un ser causa de éste? El hombre es él mismo la paradoja de un ser creado sin creador, en la medida que, indesmentiblemente, él nace a un mundo que le precede y le trasciende, a un mundo, como dice Arendt, «al que llegamos como extranjeros», pero que es también hechura humana y posibilidad de renovación de lo humano. Es este mundo el que es la condición original de todos sus privilegios, por él el ser humano actúa, se relaciona a los otros, a él nace, en él es libre, es el mundo lo que hace ulteriormente imposible que la vida humana sea concebida meramente a partir de una reducción de lo político a lo biopolítico o bien a sus márgenes, particularmente allí donde lo político sigue siendo una mera singularización o sus- 
penso de lo vivo y lo vivo un comienzo pre-político de lo político o bien su amenaza.

Finalmente, sólo nos resta decir que es la idea de mundo arendtiana la que hace crisis en esta interpretación biopolítica del pensamiento de Arendt que hemos presentado y criticado. Y esto es así precisamente por ser tal interpretación una que no podría sostener la autonomía de este concepto y su arraigo fenomenológico, que de suyo se hace refractario a toda forma de supeditación a la vida biológica y a toda remisión a las formas de biopoder o aun de resistencia a éste. Digámoslo taxativamente: No se trata aquí centralmente de la mundanidad de la libertad, sino más bien de la libertad de la mundanidad y de las condiciones de posibilidad de una fenomenología política de ésta. Todo ello excede con mucho, esperamos haberlo mostrado, los márgenes del paradigma biopolítico.

\section{BIBLIOGRAFÍA}

Agamben, Giorgio (2002): Homo Sacer. III. Lo que queda de Auschwitz. El archivo y el testigo, Valencia, Pre-textos.

Agamben, Giorgio (2003): Homo Sacer. T. I. El poder y la nuda vida, Valencia, Ed. Pre-textos.

Agamben, Giorgio (2004): Homo Sacer II, 1. Estado de excepción. Valencia, Ed. Pre-textos.

ARENDT, Hannah (1968): The origins of totalitarianism, New York, Harcourt: Brace \& Company.

ARENDT, Hannah (1984): La vida del espíritu, Centro de Estudios Constitucionales.

ArEndT, Hannah (1993): La condición humana, Bs. As., Paidós.
ARENDT, Hannah (1996): Entre pasado y futuro. Ocho ejercicios sobre la reflexión política, Barcelona, Península.

ARENDT, Hannah (1998): De la historia a la acción, Buenos Aires, Paidós.

ArENDT, Hannah (2001): El concepto de amor en san Agustín, Madrid, Editorial Encuentro.

ARENDT, Hannah (2002): Journal de pensée, 2 volumes, Paris, Éditions du Seuil.

ARENDT, Hannah (2005): The promise of politics, New York, Schocken Books.

Birmingham, Peg (2007): "The AnArchic Event of Natality and the "Right to Have Rights"), Social Research: An International Quarterly, 74 (3): 763-776.

DuARTE, André (2005): «Biopolitics and the dissemination of violence: the Arendtian critique of the present», en: http: //hannaharendt.net/research/biopolitics.html

FuENTES, Juan José (2007): «El problema de la voluntad en Hannah Arendt: ¿un debate kantiano?», Daimon, 41: 77-90.

HonIG, Barbara (1988): «Arendt, identity and difference», Political Theory, 16 (1): 77-98..

JACOBITTI, Susan (1988): «Hannah Arendt and the Will», Political Theory, 16 (1): 53-75.

KanT, Immanuel (2003): Crítica de la razón práctica, Buenos Aires, Losada.

QuinTANA, Laura (2009): «Vida y política en el pensamiento de Hannah Arendt», Revista de ciencia política XXIX (1): 185-200.

VATTER, Miguel (2006): «Natality and Biopolitics in Hannah Arendt», Revista de Ciencia Política, XXVI (2): 137-159. 


\begin{abstract}
NOTAS
1 Véase, por ejemplo, Duarte (2005); Miguel Vatter (2006); Peg Birmingham (2006); Braun (2007); Laura Quintana (2009), entre otros. No todos ellos arrancan su enfoque de la relación entre vida y natalidad, pero sí cada uno estima que esta última idea u otras afines colaboran a esta relectura. Otros, sin pretender hacer aparecer a Arendt como una pensadora biopolítica, convierten algunas de sus tesis o las consecuencias de éstas en un terreno fecundo para tal apropiación — como es el caso de Peg Birmingham, a nuestro juicio. Por razones de su alcance, radicalidad y repercusión nos restringimos aquí a la discusión con Vatter y Birmingham. De ser ambos, en lo que sigue, debidamente enfrentados y rebatidos, lo serán también los demás autores aludidos.

2 Para este punto me permito remitir a mi artículo «El problema de la voluntad en Hannah Arendt: ¿un debate kantiano?» (Fuentes, 2007).

3 «Por consiguiente, la diferencia entre las leyes de una naturaleza a la cual esté sometida la voluntad, y una naturaleza que esté sometida a una voluntad (respecto de lo que tiene relación de ella con sus acciones libres), se funda en que, en la primera, los objetos tienen que ser causa de las representaciones que determinan la voluntad, mientras que en la segunda la voluntad ha de ser causa de los objetos, de suerte que su causalidad tiene su motivo determinante en la potencia de la razón pura exclusivamente, que por ese motivo puede denominarse también razón práctica pura. Por lo tanto, son muy distintos los dos problemas: por una parte, cómo la razón pura puede conocer a priori objetos y cómo, por otra, puede ser directamente motivo determinante de la voluntad, es decir, de la causalidad del ente racional respecto de la realidad de los objetos» (Kant, 2003: 42).
\end{abstract}

